\title{
OPERATIONAL OBSERVATION OF AUSTRALIAN BIOREGIONS WITH BANDS 8-19 OF MODIS
}

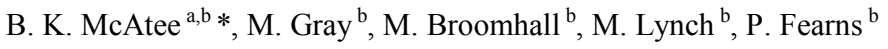 \\ ${ }^{a}$ Satellite Remote Sensing Services, Western Australian Land Information Authority (Landgate), Perth, Australia,- \\ brendon.mcatee@landgate.wa.gov.au \\ ${ }^{\mathrm{b}}$ Remote Sensing and Satellite Research Group, Curtin University, Perth, Western Australia,-- (m.gray, m.broomhall, \\ m.lynch, p.fearns)@curtin.edu.au
}

Technical Commission VIII, WG VIII/8

KEY WORDS: MODIS, Remote Sensing, Surface Reflectance, Bioregions, Australia

\begin{abstract}
:
Data from bands 1-7 are the most common bands of the MODIS instrument used for near-real time terrestrial earth observation operations in Australia. However, many of Australia's bioregions present unique scenarios which constitute a challenge for quantitative environmental remote sensing. We believe that data from MODIS bands 8-19 may provide significant benefit to Earth observation over particular bioregions of the Australian continent. Examples here include the use of band 8 in characterising aerosol optical depth over typically bright land surfaces and accounting for anomalous retrievals of atmospheric water vapour obtained using MOD05 based on the abundance of Australia's 'red dirt', which exhibits absorption features in the near infrared bands 17-19 of MODIS. Bioregion-focused applications such as those mentioned above have driven the development of automated processing, infrastructure for the atmospheric and BRDF correction of the first 19 bands of MODIS rather than only the first 7, which is more often the case. This work has been facilitated by the AusCover project which is the remote sensing component of the Terrestrial Ecosystem Research Network (TERN), itself a program designed to create a new generation of infrastructure for ecological study of the Australian landscape.
\end{abstract}

\section{INTRODUCTION}

\subsection{Background}

The Moderate Resolution Imaging Spectroradiometer (MODIS) was designed to improve the capability of satellite remote sensing to meet the needs of the global change science community (Justice, 1998). As well as addressing the global science requirements, the range of products provided by MODIS also find practical application within the areas of agricultural, natural resource and emergency services management, and increasingly within the ecological research community.

This current work is part of the Terrestrial Ecosystem Research Network (TERN) AusCover Program (www.auscover.org.au) which seeks to expand the use of remotely sensed data within the ecological research community. Under the AusCover project an archive of remotely sensed products is being compiled on nationally linked, High Performance Computing (HPC) architecture across Australia. Other themes within TERN are building infrastructure for the analysis and synthesis of a myriad of ecological data sets and will integrate with the AusCover archive.

In this paper we describe some of the MODIS processing and validation work being conducted under the AusCover project and describe selected applications of our work.

\subsection{Processing and Validation}

The MODIS processing component of this work is focused on the implementation of the Simple Method for Atmospheric
Correction (SMAC) (Rahman and Dedieu, 1994) for bands 8-19 of MODIS on the national HPC grid. It represents an extension to the operational MODIS processing system for bands 1-7 described in McAtee and Maier (2009). The inspiration for this derives from our belief that the extra spectral information contained in these bands will benefit the atmospheric correction of MODIS, and follow-on sensors such as VIIRS, under conditions typical of continental Australia.

We base the MODIS-derived, atmospherically corrected, surface reflectance validation component of this study firstly on in situ measurements of spectral reflectances collected using an Analytical Spectral Devices (ASD) spectroradiometer over spatial scales from $10 \mathrm{~m} \times 10 \mathrm{~m}$ to $600 \mathrm{~m} \times 600 \mathrm{~m}$ at a semi arid site near the town of Merredin in the Wheatbelt region of Western Australia. We are currently expanding this validation

\footnotetext{
* Corresponding author.
} 


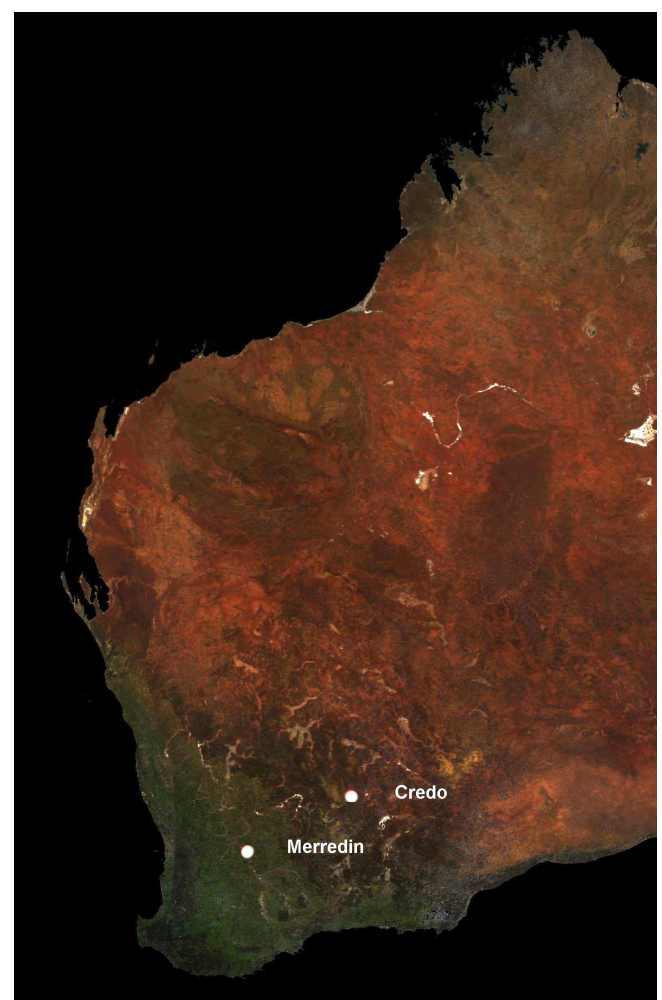

Figure 1. The location of the Merredin and Credo field sites.

component of the work under the AusCover project to include validation of MODIS vegetation products at a second field site situated on Credo Station in the Greater Western Woodlands of the Goldfields region of Western Australia. The location of the Merredin and Credo field sites are shown in Figure 1.

\section{FIELD MEASUREMENTS}

In the first phase of this study we use a pre-existing validation dataset for evaluating the accuracy of atmospherically corrected MODIS band 8-19 data. Earlier validation work (McAtee and Maier, 2009) has shown that using the SMAC methodology we have achieved atmospheric correction of MODIS surface reflectance to within the theoretical accuracy given in the Algorithm Theoretical Basis Document (ATBD; Vermote and Vermeulen, 1999 ; McAtee and Maier, 2009) in several bands, but there remains some discrepancies in others. Figure 2 shows ASD-based validation results from in situ measurements at the Merredin field site for band 1-7 of MODIS. The Accuracy (A), Precision (P) and Uncertainty (U) metrics used by Vermote and Kotchenova (2008) to evaluate VIIRS data products are used to quantify the MODIS surface reflectances against the in situ ASD measurements.

As noted above, there are some good quality comparisons (bands 1 and 3) but there is significant spread in other bands. It is the quest to improve these comparisons that leads us to examine the extra spectral information available in the other MODIS bands between 8 and 19 .

\section{APPLICATIONS}

\subsection{Vegetation Parameter and Condition Monitoring}

The Credo field site shown in Figure 3 is TERN Supersite (www.tern-supersites.net.au). Such supersites will have remote sensing data collected to support in situ vegetation measurements as well as flux tower measurements of transpiration and gas exchange. The site serves to validate MODIS-based vegetation parameters in support of larger scale ecological process modelling as well as providing further validation opportunities for our evaluation of the 19 band SMAC product. An airborne field campaign collecting hyperspectral and LiDAR data supported by ground measurements will be conducted at the site in May 2012.

As part of the Supersite data collection and validation work we aim to construct time series of parameters derived from new MODIS products from bands 8-19 band that are descriptive of ecological processes and support conservation planning in the Greater Western Woodlands region. Figure 4 shows a time series of the surface reflectance in MODIS band 18 for 2009, derived from our SMAC-based processing system. Spatial versions of such time series will be readily producible from the MODIS archive being constructed for use in applications such as vegetation condition monitoring by the ecological research community.
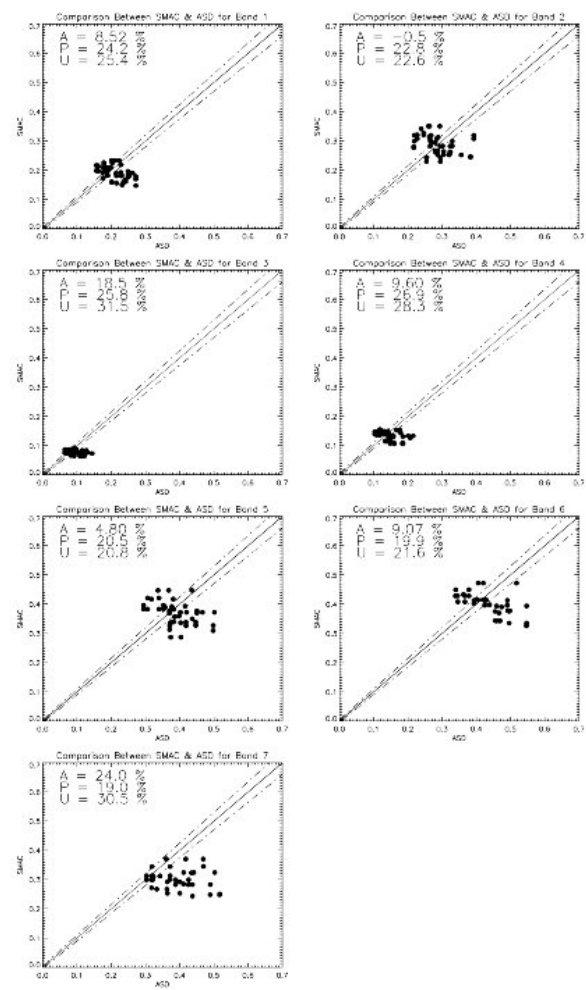

Figure 2. Atmospheric correction validation results for Bands 17 of MODIS from the Merredin field site. 


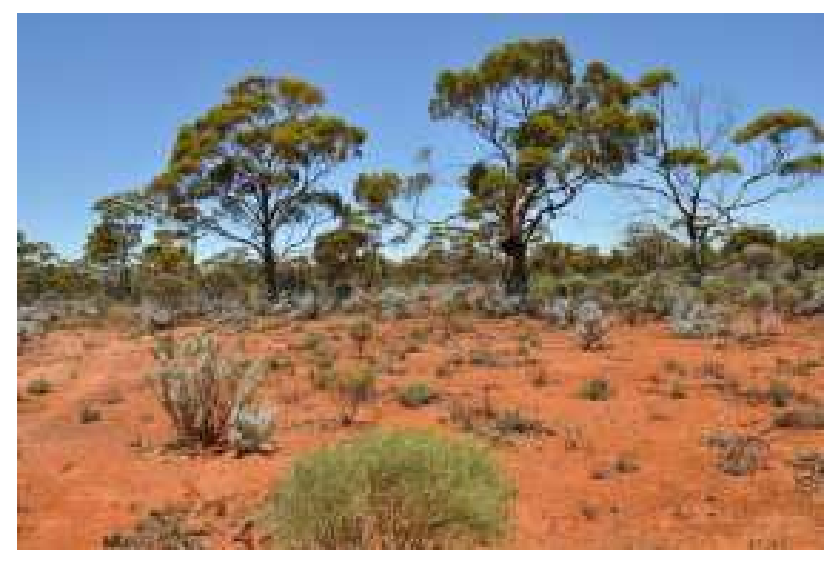

Figure 3. The Credo field site.

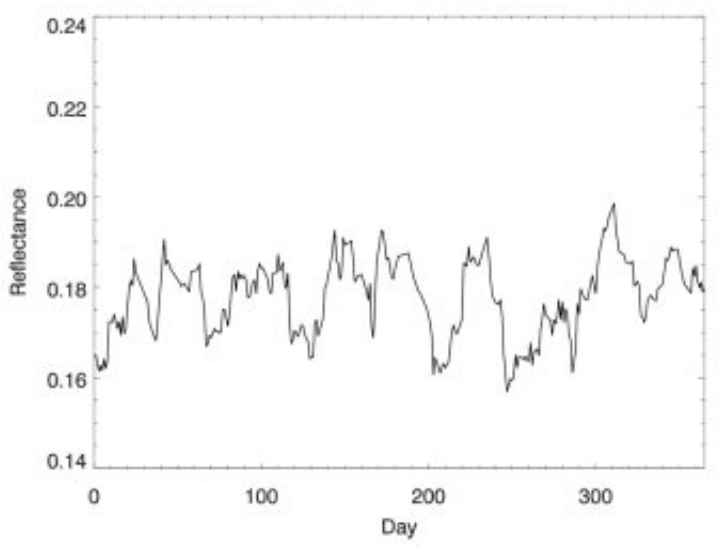

Figure 4. A time series of atmospherically corrected MODIS band 18 for 2009 representative of the Credo site.

\subsection{Reflectance Change-Based Dust Storm Detection}

As part of our AusCover work we are also extending the work of Broomhall et al (2009) in using atmospherically corrected MODIS surface reflectance data to detect dust storms. This work comes as bi-product of the need to devise new approaches to achieve accurate estimation of aerosol optical depth under Australian conditions. The typically bright land surface which exhibits sparse vegetation cover does not suits dark dense vegetation-based approaches to aerosol estimation (Broomhall et al, 2009). In this work we use the difference between the MODIS surface reflectance measurement and the surface reflectance predicted by the Bi-direction Reflectance Distribution Function (BRDF) to estimate aerosols. Such a 'reflectance change' based approach also proves effective for detecting dust storms as shown in Figure 5.

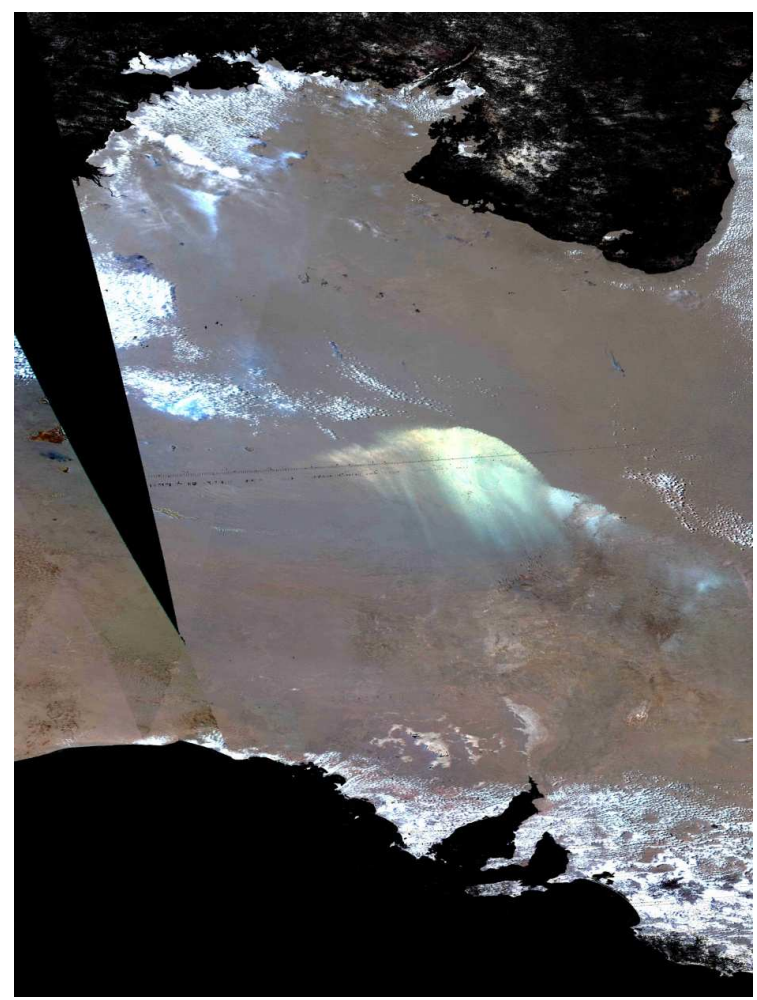

Figure 5. Dust storms detected from MODIS imagery using the reflectance change based methodology.

\section{CONCLUSION}

The AusCover project under the TERN program is compiling an archive of remotely sensed data linked to supporting in situ measurements with the aim of constructing a HPC-based research infrastructure towards a new era of ecological research and understanding.

In this work we have concentrated on developments in MODIS processing that support well-quantified atmospheric correction of surface reflectance which we envisage will underpin new applications in ecological research and earth system science.

\section{REFERNCES}

Broomhall, M, McAtee, B., and Maier, S., 2009. An investigation of the remote sensing of aerosols based on MODIS data for Western Australia. Springer Verlag series on Geoinformation and Cartography, Series Editors: Cartwright, W., Gartner, G., Meng, L., \& Peterson, M. ISSN:1863-2246.

Justice, C., et al. 1998. The Moderate Resolution Imaging Spectroradiometer (MODIS): land remote sensing for global change research. IEEE transactions on Geoscience and Remote Sensing, 36, pp.1228-1249.

McAtee, B and Maier, S., 2009. Improved near-real time atmospheric correction of MODIS data for Earth observation applications. Springer Verlag series on Geoinformation and Cartography, Series Editors: Cartwright, W., Gartner, G., Meng, L., \& Peterson, M. ISSN:1863-2246. 
International Archives of the Photogrammetry, Remote Sensing and Spatial Information Sciences, Volume XXXIX-B8, 2012 XXII ISPRS Congress, 25 August - 01 September 2012, Melbourne, Australia

Rahman, H., and Dedieu, G., 1994. SMAC: a simplified method for the correction of satellite measurements in the solar spectrum. International Journal of Remote Sensing, 15, pp.123143.

Vermote, E., and Kotchenova, S., 2008. Atmospheric correction for the monitoring of land surfaces. Journal of Geophysical Research, 113, D23S90.

Vermote, E., and Vermeulen, A., 1999. Atmospheric correction algorithm: spectral reflectances (MOD09). Algorithm Theoretical Basis Document Version 4.0t, Department of Geography, University of Maryland.

\section{Acknowledgements}

The Authors wish to thank the Terrestrial Ecosystem Research Network and AusCover program for the financial support of this work. 